\title{
Quality related principles of the South African beef classification system in relation to grading and classification systems of the world
}

\author{
P.E. Strydom ${ }^{\#}$ \\ ARC-Animal Production Institute, Private Bag X2, Irene 0062, South Africa
}

\begin{abstract}
Copyright resides with the authors in terms of the Creative Commons Attribution 2.5 South African Licence.
See: http://creativecommons.org/licenses/by/2.5/za/

Condition of use: The user may copy, distribute, transmit and adapt the work, but must recognise the authors and the South African Journal of Animal Science
\end{abstract}

\begin{abstract}
This paper addresses the principles related to different grading and classification systems of the world with specific focus on beef quality related outcomes. The paper uses the definitions that classification is a set of descriptive terms describing features of the carcass that are useful as guidelines to those involved in the production, trading and consumption of carcasses, whereas grading is the placing of different values on carcasses for pricing purposes, depending on the market and requirements of traders and consumers. The literature shows that the criteria used in grading systems rank carcasses fairly accurately according to expected eating experience of the loin muscles but not of higher connective tissue cuts of the hind and fore quarter. Criteria used in classification systems give limited descriptions of the quality related characteristics of the carcass. Only the Meat Standards Australia (MSA) cuts based grading system of Australia seeks to define or predict consumer satisfaction with a cooked meal for each cut of the carcass. Its success is based on a palatability assured critical control point (PACCP) approach to satisfy the consumer. However, MSA requires high technical skills, a well organised infrastructure and proper traceability, high level of integrity from different role players and could be very costly, involving high additional personnel cost. The South African classification system should probably focus on distinguishing between young feedlot and somewhat more mature pasture animals with different criteria within each sub category to describe the variation in product quality. Correct pre-slaughter and slaughter management (stress, weight, chilling rate, electrical stimulation, post mortem aging) could improve consistency within age group.
\end{abstract}

Keywords: Classification, grading, beef, dentition, age

${ }^{\#}$ E-mail: pstrydom@arc.agric.za

\section{Introduction}

Carcass grading or classification was established in most prominent meat producing countries during the early to middle 1900's. Over time the evolution of these systems were driven by new problems/needs or changes in production systems. The primary motivations for the development and implementation of these systems are best summarised in a report of Agriculture and Horticulture Development Board Industry Consulting on the EU classification system (AHDB Industry Consulting, 2008):

- Poor market transparency, made even more difficult by a fragmented industry;

- Poor market intelligence with regard to guidelines for price formation;

- A lack of a common descriptive language for a highly variable product;

- A production driven industry, as opposed to a market or consumer driven industry;

- Lack of consumer confidence in the retail product caused by, among other things, lack of precise description at the retail level, poor labelling and marking.

Therefore the general aims and objectives of carcass classification or grading systems would be close to those quoted by the same report:

- To provide a common language for use by those in trading livestock and carcases to facilitate trade and intensify competition; 
- To develop clearer market signals from the consumer to the producer by the use of premiums for desirable stock and discounts for less desirable stock;

- To act as a catalyst for breed and national herd/flock improvement;

- To act as a framework for the development of national price reporting schemes to enable those trading (and others such as statutory organisations) to determine what prices were paid for differing types of stock in different areas;

- To assist producers to market their stock more effectively, aided by better 'market transparency';

- To improve efficiency in transactions in what is today referred to as the 'supply chain' between producer, slaughterer and retailer; encouraging buying specifications to be used that could be filled and verified against classification descriptions;

- To allow those cutting meat to monitor and control their operations on a yield basis. Classification has a direct relationship with the amount of saleable meat in a carcase. Yields and returns from cutting and processing can therefore be predicted and monitored with a knowledge of the classification of the carcase raw material;

- To promote, by the marking or labelling of classification/grading information on meat up to the point of retail sale, a basis for 'quality' marks or promotional brands;

- To facilitate the development of any export markets.

From these it is clear that carcass classification or grading systems have been invented and are continuously being developed to describe the quality and yield of a carcass (in particular the edible part) to the benefit of all role players in the production chain and for the final purpose of a satisfied consumer. Smith et al. (2008) described the consumer process in terms of firstly a "customer" (person who purchases) whose preference is influenced by appearance characteristics (e.g. ratios of muscle, fat and bone, amount of marbling; colour of fat and lean; freedom of defects). The quality of cooked meat is then evaluated by a "consumer" in terms of palatability characteristics (e.g. flavour, juiciness, tenderness). Therefore both yield factors (fat, bone, meat) and eating quality will influence consumer preferences, but most consumer surveys suggest that eating quality (defined by most consumers simply as 'taste') is a primary driver of food purchase decisions (Quinn, 1999; Tatum, 2006; Shook et al., 2008).

While the aims and objectives of grading and classification are broad, the uptake by sectors of the industry will probably depend on factors such as:

- Accuracy - It will sort beef carcasses consistently into meaningful and marketable groups using applied science.

- Simplicity - All segments of the industry must have a working knowledge of the system.

- Ease of application - It can be implemented with a minimum amount of time and effort - most of the time on-line or at least before the carcass is sold.

- Cost - It does not require expensive equipment.

- Measures against tampering - It should be easy to monitor or verify correctness and once a grade/class is awarded it can not be changed.

The aims of this document is to give a short overview of the grading and classification systems of the world, then to identify the criteria in these systems that are involved in the description/prediction of eating quality. Successes and/or shortfalls related to these criteria will then be discussed with specific reference to the South African system.

The definitions proposed by AHDB Industry Consulting (2008) are adopted in this paper. Classification describes all of the scores or measurements for important value traits according to a common descriptive language. The carcass is then presented to the wholesaler or retailer listing all the attributes that have been evaluated. Grading is defined as the placing of different values on several carcass characteristics and using different combinations of these characteristics to develop a grade for pricing purposes, depending on the market and requirements of traders and consumers. Generally this involves ranking carcasses in a hierarchy for the traits of interest to a wide variety of trade and consumer preferences.

\section{Criteria used in various beef classification and grading schemes over the world}


Globally certain countries or regions have focussed more on yield (EU carcass classification scheme; AHDB Industry Consulting, 2008); others have adopted a dual system attempting to describe or grade both yield and quality (USDA carcass grading scheme - Smith et al. (2008); South African carcass classification scheme - Government Notice No. R.342 of 19 March 1999; the AUS-MEAT system - Anon (2006a) or meat quality/palatability only (MSA cuts based grading - Polkinghorne et al., 2008).

The history of the origin and evolution of major grading and classification schemes of the world were reviewed by Polkinghorne \& Thompson (2008) and will not be repeated in detail in this document. However, Table 1 was adopted from this work and describes the principal components of these schemes and also distinguishes between grading and classification systems and operational area.

Of the seven countries discussed, only the European (EUROP), South African (SA) and the AUSMEAT system of Australia are regarded as classification systems. Of the grading systems, all but the Meat Standards Australia (MSA) cuts based grading system has separate yield and quality grades. The latter system will be discussed later in more detail due to its unique nature.

In terms of "Ease of application", the AUS-MEAT and MSA are the only systems using pre-slaughter criteria, while these two and the other grading and classification systems perform measurements on the slaughter floor. Chiller assessments, in addition to slaughter floor assessments, are used by all but the EUROP and SA systems, while the MSA system does post-chiller recordings

Conformation, shape or rib eye area (REA), some form of fat measurement, carcass weight and sex are common criteria for all systems and are recorded on the slaughter floor and/or during chiller assessment. All except sex are used for yield predictions but are also incorporated into quality grades in grading systems and to lesser extent it contributes to descriptions related to meat quality (such as the SA system).

Age or maturity, and marbling seem to be the main criteria used for quality grading and classification. Age or maturity is determined by dentition in the SA and AUS-MEAT systems. Meat Standards Australia, the Canadian and USDA grading systems use ossification score instead. Other characteristics that may be used to (but not limited to) describe maturity are meat texture, meat colour (or brightness) and lean maturity, and are used in the MSA, USDA, AUS-MEAT, Canadian, Korean and Japanese systems. The Korean system uses ossification in their yield grades. Fat characteristics are also used for quality grades by the Canadian, Korean and AUSMEAT systems, while the Japanese system include fat lustre, firmness, and texture (Beef Fat Standards - BFS). All fat and meat/muscle appearance, quantity and texture scores are performed visually or with the aid of standards (charts).

The combinations in which the scores for the various characteristics are used to form a quality grade are rather interesting and are described in more detail by Smith et al. (2008) and Polkinghorne \& Thompson (2010). A few could be mentioned which have relevance to further discussion in this document.

The USDA system is well-known for using marbling as one of its main criteria in combination with maturity and type/sex of the animal. The Official United States Standards for Grades of Carcass Beef define 'quality grade' as 'the palatability indicating characteristics of the lean', and state that: 'for steer, heifer and cow beef, quality of the lean is evaluated by considering its marbling and firmness as observed in a cut surface in relation to carcass evidences of maturity (Anon, 2001). The eight quality grades are Prime (Pr), Choice (Ch), Select (Se), Standard (St), Commercial (Co), Utility (Ut), Cutter (Cu) and Canner (Ca) for which there are firstly gender and type limitations (e.g. bulls are not quality graded, cows can not be graded Prime, and bullocks are graded separately from steers, heifers and cows). The first three grades are mostly related to retail table cuts. After distinguishing sex and gender, grades are formed by a combination of marbling and maturity in such a way that the higher the maturity (older), the stricter the marbling scores, i.e. the marbling cut-off category for Choice is higher than for Prime and so on, so that more mature carcasses have to make up for age by having more marbling, so to speak. Maturity is determined by evaluating the size, shape and ossification of the bones and cartilages - especially the split chine bones - and the colour and texture of the lean flesh. Five maturity groups (A - E) are used with "position within each group" (e.g. $\mathrm{A}^{00}$, $\mathrm{A}^{20} \ldots \mathrm{A}^{100}$ ) determined by ossification of split chine bones of the vertebral column, size and shape of rib bones (becomes wider and flatter with less blood in old animals), colour of muscle (older becomes darker), and texture of muscle (older becomes coarser). Nine marbling scores are used: abundant (AB), moderately abundant (MA), slightly abundant (SA), moderate (MD), modest (MT), small (SM), slight (SL), traces (TR) and practically devoid (PD), and are based on amount, size of blots and distribution of blots. The percentage of intramuscular fat is 1.8 for the lowest marbling degree (PD), increases 1.2 per degree, and is 11.7 for the highest marbling degree (AB) (Savell et al., 1986; Lunt et al., 1989). 
The Canadian system distinguishes between youthful and old (cows and bulls) by ossification with grades for each of the two categories (Anon, 2009). Other measurements like fat colour, and lean texture and colour are used to further distinguish grades in both categories. Top youthful grades exclude yellow fat and require better muscling and firm lean texture. One grade is reserved for bulls.

It is interesting to note that quality grades used by the Korean and Japanese systems do not include age of the animal per sé (dentition or ossification score). The Japanese system uses the scores of all seven quality parameters mentioned in Table 1 to allocate carcasses to 1 of 5 quality grades. The same applies to the Korean system but with six parameters.

The British and rest of Europe's classification systems evolved over many years and were combined into a single system (EUROP) in 1981 (AHDB Industry Consulting, 2008) with the main objective to describe carcasses for those involved in slaughtering, cutting, distribution and retailing according to terms relevant to trading. At the time of the schemes' development it was appreciated that meat quality, in all its guises, was of importance to the meat trader and also of principal interest to the consumer in the form of eating quality. However, they argued that since no practical, reliable and cost-effective measure emerged from many research initiatives over years, the system remained focussed on yield classification. The procedures like those captured in the MLC Blueprint in the United Kingdom for quality beef could be adopted by sectors of the industry to ensure quality (AHDB Industry Consulting, 2008). The French as another example use official quality and origin signs as quality indicator on products, such as "Organic farming" or "Label Rouge". These are therefore audited brand marks aiming at describing authenticity or controlled processes like in the MLC Blueprint and do not include quality identifiers. To the Europeans, the final decision regarding the inclusion of quality in classification was to describe quality accurately by single or combined carcass parameters, or leave it out of the system.

In the interest of the scope of this document, the history of the SA system will be described a bit more thoroughly. The SA beef description system has also evolved over a number of years from 1932. Age of the animals has been used since 1936 as a characteristic to grade carcasses, presumably because carcasses of younger cattle were considered to be of "better" quality than those of older cattle (Government Notice No. 1548 of 1936). Permanent incisors was used for the first time in 1949 when "A" indicated carcasses of younger animals with not more than 6 teeth and "B" indicated carcasses of older animals with more than 6 teeth, but which were not older than 4 years (Government Notice No. 992 of 1949). In 1951, a class "C" for carcasses of the oldest animals was used for the first time (Government Notice No. 846 of 1951). In 1970, the "Super A" grade was allocated only to carcasses of animals with no permanent incisors and the "Super B" grade only to carcasses of animals with 1 tooth or more, but with not more than 4 teeth (Government Notice No. 1730 of 1970). Less than a year later, the grades, "Super A" and "Super B", were combined as "Super" for carcasses deriving from animals with not more than 2 teeth. The age class "A" was used in the grades "Prime A" and " $1 \mathrm{~A}$ " for carcasses of animals with no more than 2 teeth; the age class "B" in the grades "Prime B" and "1B" was allocated to carcasses which derived from animals with not less than 3 and not more than 6 teeth, and the age class " $C$ " in the grade " $1 C$ " to carcasses which derived from animals with more than 6 teeth, not older than 5 years (Government Notice No. R.1239 of 1971). In the research of Klingbiel (1984) it was found that A-age animals had significantly higher muscle collagen solubility, that muscle pigment concentration was significantly lower, and that the cooking loss (\%) was significantly lower. These results would be generalised by saying that the meat of A-age animals (not more than 2-teeth) was more tender, lighter coloured and juicier than meat from older animals. Through a series of discussions by various working groups and committees a proposal was accepted to define the age classes as A: 0-tooth; B: 1- to 6-teeth; and C: 7- to 8-teeth (Government Notice No. R.1010 of 1981). The Namibian Carcass Classification System is still based on these principles in attempt to ensure the production of consistent quality meat (tenderness and fatness). Further research in the early 1990's confirmed previous work and showed that meat tenderness decreased, as the slaughter age of the animals increased, in the order of $0,2,4$, 6 and 8 permanent incisors. Samples of meat from animals with no permanent incisors were significantly more tender than those of the animals with 2 permanent incisors. The 2-, 4- and 6-teeth animals were not appreciably different in terms of tenderness. In spite of these results, some still denied their validity and exerted pressure on the authorities to eventually classify the carcasses of 2-teeth animals in a separate age class (AB) than the 3- to 6-teeth animals (B) and 0-tooth animals (A) (Government Notice No. R.342 of 1999). 
The Australian system described as both MSA and AUS-MEAT in Table 1 seems confusing, but in fact describes two interrelated parts of a common system. Initially, Australian grading described grading 
Table 1 Principal components of selected beef classification and grading schemes in selected countries around the world (Adopted from Polinghorne \& Thompson, 2010)

\begin{tabular}{|c|c|c|c|c|c|c|c|c|}
\hline Country & Canada & Europe & Japan & South Korea & $\begin{array}{l}\text { Republic of } \\
\text { South Africa }\end{array}$ & USA & \multicolumn{2}{|c|}{ Australia } \\
\hline Scheme & Canada & EUROP & JMGA & Korea & South Africa & USDA & AUS-MEAT & $\begin{array}{l}\text { Meat Standards } \\
\text { Australia }\end{array}$ \\
\hline Grading Unit & Carcass & Carcass & Carcass & Carcass & Carcass & Carcass & Carcass & Cut \\
\hline Classification & -- & Yes & -- & -- & Yes & -- & Yes & -- \\
\hline Quality Grade & Yes (4) + (5) & -- & Yes (5) & Yes (5) & -- & Yes (8) & -- & Yes (3) \\
\hline Yield grade & Yes (3) & -- & Yes (3) & Yes (3) & -- & Yes (5) & -- & -- \\
\hline Pre-slaughter & -- & -- & -- & -- & -- & -- & Grain fed & $\begin{array}{l}\text { Bos indicus \% } \\
\text { HGP implants }\end{array}$ \\
\hline \multirow[t]{2}{*}{ Slaughter floor } & Carcass weight & $\begin{array}{c}\text { Carcass weight } \\
\text { Sex }\end{array}$ & Carcass weight & Carcass weight & $\begin{array}{l}\text { Carcass weight } \\
\text { Dentition }\end{array}$ & Carcass weight & $\begin{array}{l}\text { Carcass weight } \\
\text { Dentition }\end{array}$ & $\begin{array}{c}\text { Carcass weight } \\
\text { Sex }\end{array}$ \\
\hline & $\begin{array}{c}\text { Sex } \\
\text { Conformation }\end{array}$ & $\begin{array}{c}\text { Fat cover } \\
\text { Conformation }\end{array}$ & Sex & Sex & $\begin{array}{c}\text { Visual fat cover } \\
\text { Conformation } \\
\text { Sex }\end{array}$ & Sex & $\begin{array}{c}\text { P8 fat } \\
\text { Sex } \\
\text { Butt shape }\end{array}$ & $\begin{array}{c}\text { Electrical stimulation } \\
\text { Hang }\end{array}$ \\
\hline Chiller & $\begin{array}{l}\text { Marbling score } \\
\text { Meat colour } \\
\text { Meat texture } \\
\text { Fat colour } \\
\text { Fat thickness } \\
\text { Skeletal } \\
\text { development }\end{array}$ & -- & $\begin{array}{c}\text { Marbling score } \\
\text { Meat colour } \\
\text { Meat brightness } \\
\text { Fat colour } \\
\text { Fat luster } \\
\text { Fat texture } \\
\text { Fat firmness } \\
\\
\text { EMA } \\
\text { Rib thickness } \\
\text { Fat thickness }\end{array}$ & $\begin{array}{l}\text { Marbling score } \\
\text { Meat colour } \\
\text { Fat colour } \\
\text { Firmness } \\
\text { Meat texture } \\
\text { Lean maturity } \\
\text { EMA } \\
\text { Fat thickness }\end{array}$ & -- & $\begin{array}{c}\text { Marbling } \\
\text { Ossification score } \\
\text { Meat colour } \\
\text { Meat texture } \\
\text { Rib fat } \\
\text { EMA } \\
\text { Kidney and perirenal fat }\end{array}$ & $\begin{array}{l}\text { Marbling score } \\
\text { Meat colour } \\
\text { Fat colour }\end{array}$ & $\begin{array}{l}\text { Marbling score } \\
\text { Ossification score } \\
\text { Meat colour } \\
\text { Hump height } \\
\text { Ultimate pH }\end{array}$ \\
\hline Post Chiller & -- & -- & -- & -- & -- & -- & -- & $\begin{array}{c}\text { Ageing time } \\
\text { Cooking method }\end{array}$ \\
\hline
\end{tabular}


standards in terms of conformation, fat cover and age as first, second and third grade, implying a decrease in quality (Anon, 1974). This was later replaced by the AUS-MEAT language reflecting a deliberate change from a subjective quality rating to a specification in terms of sex, dentition and carcass weight without any connotation to quality. The reasoning behind this classification (not grading) was that to different sectors, different specifications translate to top quality, e.g. the hamburger market will rather use fatter older animals, while the restaurant trade needs younger, leaner carcasses. The AUS-MEAT system evolved further over years with the inclusion of chiller assessment standards for fatness, marbling, meat colour, fat colour and REA (Anon, 2006a). Other developments also include precise descriptive language for carcass cuts and collectively these serve the domestic but especially the export trade. With the recent development of the MSA cuts based grading system for the domestic market, the base components of AUS-MEAT (sex, dentition, carcass weight and rib fat) proved ineffective as predictors of eating quality and additional refined factors were added including ossification and marbling. Pre-slaughter inputs including Bos indicus content, the use of hormonal growth promoters (HGP) were added together with processing factors such as carcass suspension method (tender-stretch), and post mortem $\mathrm{pH} /$ temperature decline. Finally, post processing inputs of days aging and cooking method by muscle were added (Polkinghorne et al., 2008). The descriptive language for these traits is captured in AUS-MEAT documentation.

\section{How do these systems perform and how reliable are their criteria?}

Various studies have investigated the accuracy of classification or grading criteria to predict or describe quality or to rank carcasses according to quality. All of these studies have their limitations simply because all factors can not be addressed in a single study, or the measuring tools used are not faultless and/or very often these subjects are addressed from a specific industry's perspective.

Maturity measured by ossification (with or without lean maturity) or dentition, and marbling are probably the most common criteria used in all quality grading or classification systems. Smith et al. (2008) gave a thorough overview of the suitability of the USDA system (using both maturity and marbling) as grading system. Smith et al. (2008) reported that the philosophy used in the grading of any agricultural commodity involves sorting of the products into groups - usually in some hierarchical fashion that differ in utility, desirability and value. The authors emphasise the fact that the USDA quality grades were never intended to provide point estimates for expected beef palatability and that neither quality grades nor palatability ratings are perfectly assigned because both are subjective estimates. Furthermore a single muscle is used as reference or predictor of the whole carcass. There are numerous studies that evaluated the USDA system for various measures of efficiency and suitability. From most of these it is important to note that not only tenderness is evaluated but rather the grading systems effect on overall experience, palatability or acceptability that includes other measurements such as flavour, juiciness, visual appeal, etc. Only a few relevant to this discussion will be reviewed. The study of Smith et al. (1987) described the ranking ability of the system across all the grades and reports that USDA quality grades (marbling and maturity) only accounted for 40 to $47 \%$ of the observed variation in overall palatability (sensory scores) of dry heat-cooked (broiled) loin and top round steaks (topside) and 25 to 33\% of the variation in shear force (mechanical measurement) for loin, top round (topside), bottom round and eye-of-round steaks (silverside). The difference between the two prediction values also indicates the effect of measuring tool (shear force vs. sensory panels). Mean overall palatability ratings (sensory scores between 1 and 8 ) for loin steaks were 6.0 (Pr), $5.7(\mathrm{Ch}), 5.3(\mathrm{Se}), 4.6(\mathrm{St}), 4.9(\mathrm{Co}), 4.0(\mathrm{Ut}), 3.4(\mathrm{Cu})$ and $2.8(\mathrm{Ca})$, with $P<0.05$ significance for differences across the categories, except for $\mathrm{Cu}$ and $\mathrm{Ca}$. When all sensory panel ratings (tenderness, connective tissue, flavour, juiciness) and shear force values were combined in a single "desirability" score, percentages of loins steaks rating "very desirable" were $63.6(\mathrm{Pr}), 49.4(\mathrm{Ch}), 35.3(\mathrm{Se}), 20.3(\mathrm{St}), 30.3(\mathrm{Co})$, $11.1(\mathrm{Ut}), 3.2(\mathrm{Cu})$ and $0.0(\mathrm{Ca})$. Smith et al. (2008) reported that in the USA the beef quality grades actually used in commerce are those for carcasses from cattle less than 42 months of age (nominally) - Pr, $\mathrm{Ch}$, Se, with St essentially never sold as such at retail because of the negative connotation of the term. Quality grade predicted flavour, tenderness and overall palatability of loin steaks with $30-38 \%$ accuracy, but could not explain more than $8 \%$ of variation in panel ratings of the top round (higher connective tissue).

With regards to marbling and when only the top maturity classes were considered (A and B), the percentage of steaks with a composite of sensory panel ratings (overall palatability, flavour, tenderness, juiciness) of $\geq 6.00$ and a shear force value of $\leq 3.63 \mathrm{~kg}$ (margins for acceptability) was $66,59,56,48,41,33$, 21 and $15 \%$ for loin steaks and 18, 19, 5, 13, 8, 12, 5 and $8 \%$ for round steaks (topside or silverside) from 
carcasses with moderately abundant (MA), slightly abundant (SA), moderate (MD), modest (MT), small (SM), slight (SL), traces (TR) and practically devoid (PD) marbling, respectively (Smith et al., 1984). Therefore the effect of marbling on acceptability and its ability to rank was more evident in loins than in round steaks (topside, silverside) and also showed more significant changes over marbling levels for the loin. Furthermore, the effect of marbling (measured in the loin) on palatability of round steaks was less than for the loin especially at lower levels which suggests that connective tissue effects became more prominent. Considering the acceptability scores reported above it is interesting to note that less than $21 \%$ consumers in the study of Smith et al. (1984) would have regarded loins typical to the SA market as acceptable since the percentage marbling is generally less than the $3 \%$, which is the average marbling for the TR marbling class (second from bottom).

On maturity scores, Smith et al. (1984) reported that A-maturity carcasses produced 'very desirable' loin steaks 1.2, 1.5 and 8.0 times and 'acceptable' loin steaks 1.0, 1.1 and 1.6 times as often as did carcasses of B-, C- or E-maturity carcasses, respectively. For round steaks (with higher collagen) 'very desirable' scores were given 3.0, 3.3 and 5.7 times, and 'acceptable' scores 1.4, 1.5 and 3.1 times, respectively as often in A-maturity compared with of B-, C- or E-maturity. Therefore up to 72 months of age and even older carcasses, consumers regarded loin as very similar in terms of "very desirable" or "acceptable, but maturity scores differentiated more clearly in high connective tissue cuts, which is to be expected and also reported for the SA classification system (Klingbiel, 1984). Using one muscle as indicator seems to be a common problem in grading and classification systems. In this regard, Smith et al. (2008) reviewed several studies involving the loin muscle as single predictor muscle and concluded that the loin (m. longissimus) is an imperfect but very useful predictor of the tenderness of most of the major muscles in the beef carcass.

Dentition probably describes chronological age of the animal the best despite variation experienced among breed types and nutritional plane (Steenkamp, 1970; Weiner \& Forster, 1982; Lawrence et al., 2001). Lawrence et al. (2001) regarded a dentition based system more accurate than the USDA maturity-based (bone ossification/lean maturity) system to sort carcasses into age groups. Furthermore, they reported that cattle with 2, 4, 6 and 8 incisors were placed in more youthful categories of USDA maturity groups than they should have. In fact, $40 \%$ carcasses with 8 incisors were still classed as A maturity in the USDA system. The work of Rodas-Gonzalez et al. (2009) showed a good correspondence between USDA based maturity scoring and dentition based age, although this study did not address the effect of age or maturity on consumer acceptability. Lawrence et al. (2001) found very poor relationships between shear force or sensory panel tenderness of the loin muscle and age classed according to dentition. Strangely, USDA maturity scores, marbling scores and colour scores also correlated poorly with sensory scores but showed significant correlations with Warner Bratzler shear values. Wythes \& Shorthose (1991) reported a similar lack in shear force differences among dentition groups of cattle from Northern Australia and stated that part of the reason could have been that younger animals were leaner, chilled faster and therefore were subjected to myofibrillar shortening (cold shortening). Shorthose \& Harris (1990) avoided the cold shortening effect by application of electrical stimulation and reported an age related decrease in tenderness (shear force and sensory panel) as age progressed from one to 60 months. In Australia, MSA elected to move away from dentition score as indication of age/maturity of the AUS-MEAT and use weight for age and ossification score instead. The SA system has relied on dentition as only parameter to categorise (or describe) carcasses into potential tenderness groups since 1949. As reviewed earlier in this document, changes in the definitions or criteria of age classes varied over years until the latest adjustment was accepted in 1999 that $0,1-2,3-6$ and $>6$ permanent incisors will distinguish $\mathrm{A}, \mathrm{AB}, \mathrm{B}$ and $\mathrm{C}$ age classes. This was despite earlier findings that showed the A class was significantly more tender than the other classes for the $m$. longissimus (loin) and m. gluteobiceps (silverside) (Crosley et al., 1994). Carcasses with 2, 4 and 6 permanent incisors did not differ significantly in sensory panel scores for the loin muscle, although mean values decreased numerically. Shear force values were not different among age groups (0 to 8 incisors) and large variations within age group occurred. Carcasses used in the study were all electrically stimulated, were of similar weight and fatness and no $\mathrm{pH}$ abnormalities occurred. Differences in the sensory scores and shear values were more pronounced between the 0 tooth group and the 2, 4 and even 6 teeth groups, when a muscle, $m$. gluteobiceps, with higher collagen content was used. Bouton et al. (1978) and Shorthose \& Harris (1990) reported similar results and also emphasised that method of cooking, type of muscle, restriction of shortening of the muscle (through suspension method or electrical stimulation) interacted with one another, bringing out various results with regard to differences in age. Nevertheless, they concluded that the older animals get, the tougher 
the meat mainly due to connective tissue hardness or heat stability, hence the greater effect on high connective tissue muscles. The same line of reasoning was adopted later by Polkinghorne et al. (2008) when they developed the MSA beef grading system, which will be discussed later. Regarding muscle type and age related tenderness, Shorthose \& Harris (1990) reported that the deep breast muscle ( $m$. pectoralis profundus), and some muscles from the buttock ( $m$. gluteobiceps and $m$. semitendinosus of the silverside) were unacceptably tough before two years of age, the $m$. vastus lateralis and $m$. rectus femoris of the knuckle and $m$. semimembranosus, $m$. gracilis and $m$. aductor femoris of the topside became unacceptable after two years of age. The loin ( $m$. longissimus) (LD), fillet (m. psoas major) and rump ( $m$. gluteus medius and top $m$. gluteo biceps) were acceptable in tenderness up to 48 months of age which coincide with 6 to 8 permanent incisors. The benchmark for acceptability is of course ambiguous but nevertheless this work demonstrates the relative effect of age on tenderness. For this study they merely used a value as cut-off point for acceptability while classification would rather describe the product, and grading would categorise and relate the product to various levels of satisfaction potential. Shorthose \& Harris (1990) also found that the LD is a very poor muscle to use as reference for prediction of tenderness. South African work completed at the same time as the work of Crosley et al. (1984), but published recently confirmed an age related increase in heat-stability of connective tissue (collagen) and that the higher the collagen content of a cut, the more it will be affected by age even when the correct cooking method is used (moist heat cooking) and even when the collagen solubility is high (Schönfeldt \& Strydom, 2011).

While age by dentition is the only quality related criteria in the SA classification system, sufficient evidence exist to show that factors other than age (extrinsic or intrinsic) may have an effect on tenderness. These factors may even overshadow the effect of age depending on the type of muscle (muscle composition in terms of fibre type and connective tissue content) and position in the carcass (which relate to shortening of the fibres) and environmental conditions and inputs. In two recent studies, effects of age, production system (including nutrition) and abattoir practice on tenderness were investigated (Van Wyk et al., 2008; Frylinck et al., 2009) (Figure 1).

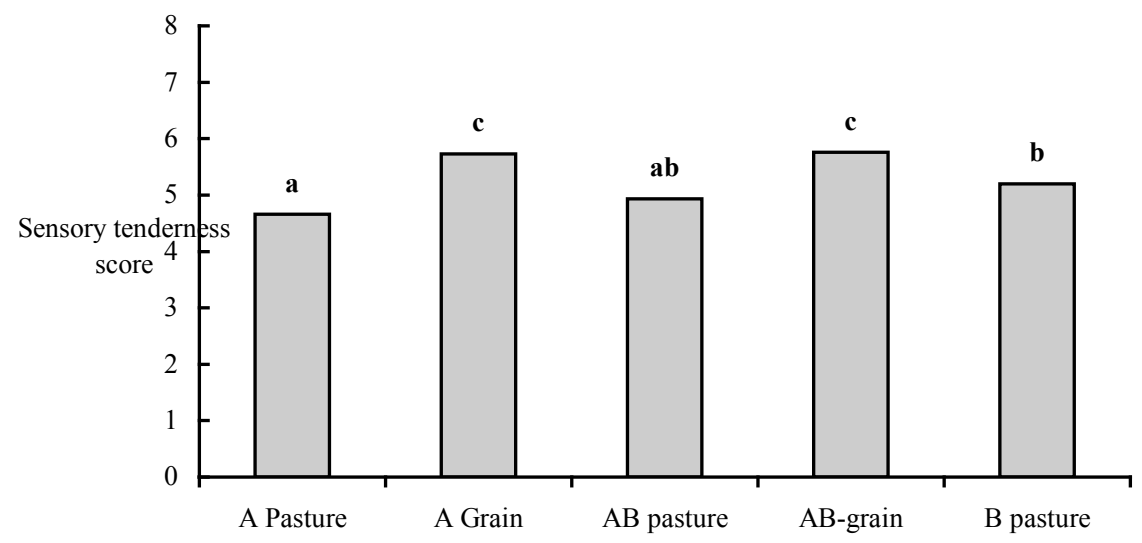

Figure 1 The effect of age class (by dentition) and production system on sensory tenderness scores of m. longissimus (Van Wyk et al., 2008; Frylinck et al., 2009) ( ${ }^{\mathrm{a}, \mathrm{b}, \mathrm{c}}$ Bars with different superscripts differ significantly, $P<0.05$; Sensory tenderness: 1 - extremely tough; 8 - extremely tender).

Loin steaks of carcasses of feedlot animals with either 0 (Class A) or 2 (Class AB) incisors were more tender (sensory panel and Warner Bratzler shear force) than steaks of loin steaks of carcasses coming from pasture animals aged according to incisors from 0 to 6 or $\mathrm{A}, \mathrm{AB}$ and $\mathrm{B}$ age classes. Among the pasture animal groups, animals with no permanent incisors (A class) produced tougher steaks than animals with 3 to 6 incisors (B class) and animals with 3 to 6 incisors had numerically better tenderness scores than animals with 1 to 2 incisors (AB class). The poor performance of the very young pasture animals (A class) could be related to poor conditioned small carcasses which reflects poor growth rate and chilled faster and therefore 
was prone to cold shortening of the loin (even though electrical stimulation was applied). Shackelford et al. (1994) and Perry \& Thompson (2005) reported more tender meat for faster growing animals within the same group, which Shackleford et al. (1994) related to lower calpastatin activities (hence better aging ability of muscle). Purchas et al. (2002) reported similar effects and stated that growth path (i.e. growth rate determined by feeding) or growth potential (genetic) had the same effect, namely, older animals and poorer market condition for slow growers; but interestingly, they also showed an advantage in aging potential of fast growers but gave no results on connective tissue properties. In another study the effects of harvesting and post-harvesting processes on animal age were demonstrated (Anon, 2006b). Electrically stimulated carcasses produced more tender loin steaks generally (over all age groups). No significant differences were recorded between 0 (A class) and 2 incisors (AB class) for pasture and feedlot and 4 and 6 incisors (B class) for pasture animals, but the older groups recorded numerically lower scores (Figure 2). Eight (8) incisors (C Class) scored significantly lower sensory tenderness scores. For non-stimulated samples, much more variation occurred within (data not shown) and between age groups, and 2, 4 and 8 incisor groups gave the lowest scores (data not shown). Stimulation had a significant effect on loin tenderness for all age groups. Both these studies demonstrate that correct abattoir practice and/or nutrition/growth rate could affect tenderness as much or more than age of the animal, at least for the loin muscle (since other muscles were not evaluated).

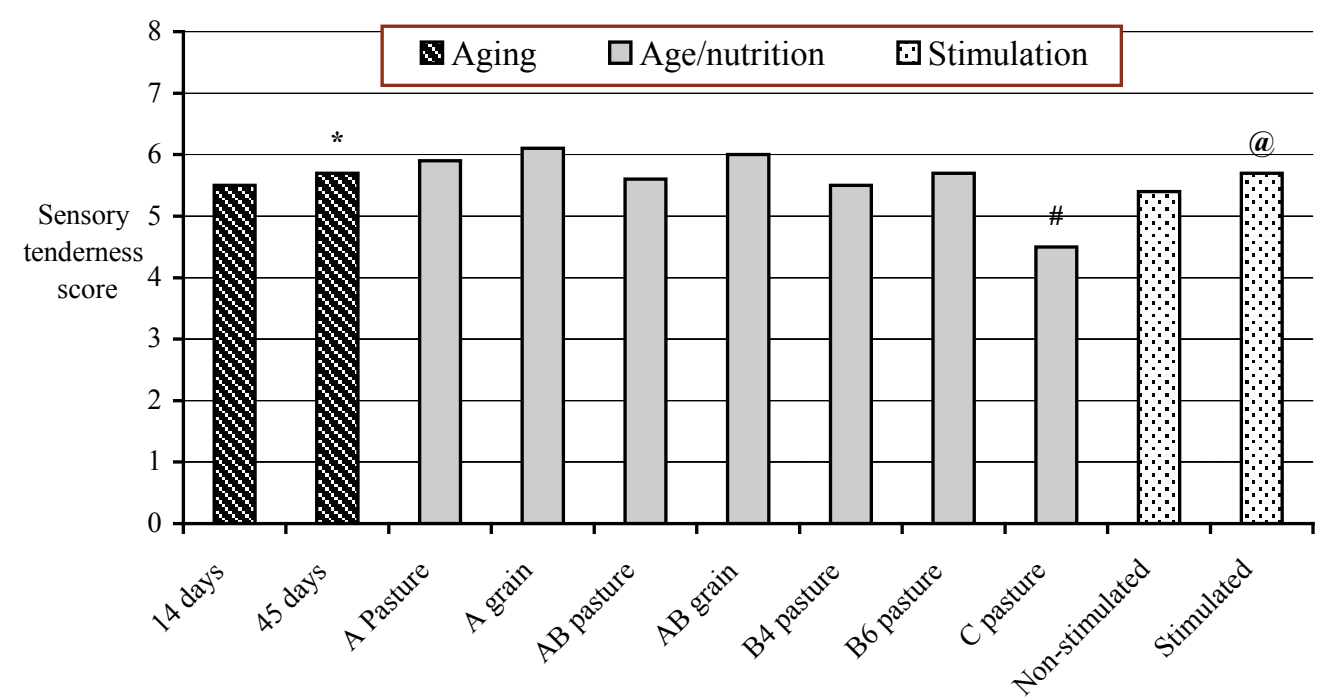

Figure 2 The effect of age class (by dentition), production system, electrical stimulation and prolonged post mortem aging on sensory tenderness scores of $m$. longissimus (Anon, 2006b)

(* - 45 days significantly more tender than 14 days; ${ }^{*}$ - C-pasture significantly tougher than all other age groups; ${ }^{\circledR}$ - Stimulated significantly more tender than non-stimulated; $\left.P<0.05\right)$.

When the present classification system in South Africa was established and developed, the changes that took place over time (as described earlier) probably reflected the changes that occurred in industry, such as the introduction of feedlots in the 1970's that increased the production of young grain-fed cattle. The criteria used at the moment were also established during a time when production systems were fairly standard and most animals were slaughtered in large state owned abattoirs that operated according to the same standards in terms of pre-slaughter (lairage time), slaughter (electrical stimulation) and post-slaughter (chilling) procedures. In the past two decades much has changed when the industry deregulated, production processes changed and an increased integration of production, slaughtering and processing occurred. Therefore it could be argued that age classification alone may not be as sufficient anymore to describe a product with regard to quality, more specifically tenderness, as two decades ago because effects other than 
age and a lack of consistency in the inputs before and during slaughter of the animal may have a greater effect on the final product quality than age. Considering the feedlot industry that represents the largest portion of carcasses produced in the SA market, hormonal growth promotants (HGPs) are widely used. Studies have shown variable effects on tenderness and eating quality, differences are often small and difficult to measure and are influenced by the number and type of HGPs used, animal breed and duration and type of post-slaughter treatment such as aging (Hunter, 2010). It was, however, concluded by Watson et al. (2008c) and Hunter (2010), in controlled studies that they do have a negative effect especially with repeated applications, combination of substances and aggressiveness of substances. Nevertheless, judged by the magnitude of their effects, the use of beta agonists (always in combination with HGP) that were only introduced at the end in the late 90's to early 2000, has a much greater negative effect on eating quality (tenderness specifically) (Dunshea et al., 2005) and while abattoir procedures (such as electrical stimulation) and post mortem aging overcome most of HGPs' effect, this is not achieved with beta agonists (Hope-Jones et al., 2010).

When the variation in procedures directly before slaughter, during and after slaughter is considered in addition to production factors affecting meat quality the problem becomes more complex. Electrical stimulation has been discussed in relation to age but its true effect is only revealed when both the comparisons of stimulation $v s$. no stimulation and the correct application of stimulation are taken into account. Referring back to the state owned abattoirs of two decades ago, the slaughter process (including stimulation) was standardised, while today various scenarios (no stimulation, ineffective stimulation, over stimulation) of incorrect procedures occur due to the fragmented industry and smaller units. The impact of this state of affairs is demonstrated by various studies (Hwang \& Thompson, 2001a; b; Hwang, et al., 2003; Strydom et al., 2005).

It is probably safe to conclude that the South African classification system at present distinguish between feedlot animals (mostly A-age, with $1-2 \%$ AB class animals and very few A age pasture animals), younger pasture animals (AB), older pasture animals (B) and cull animals (C). When the work of Strydom et al. (2005), Van Wyk et al. (2008) and Frylinck et al. (2009) on the interaction between age and production system (nutrition), the work of Strydom et al. (2006) and others on electrical stimulation and the work of Strydom et al. (2010) and others on the beta agonists are considered, distinction, and therefore price differential, between $\mathrm{A}, \mathrm{AB}$ and $\mathrm{B}$ is unfounded if based on tenderness alone - in particular that of the loin (and other low connective tissue cuts). Although the definition of a classification system is that it "describes all of the scores or measurements" only and does not rank for quality and pricing purposes, the probability of experiencing a "bad steak" (low connective tissue) in the A class (feedlot) has probably increased since the implementation of the current system. However, the fact that the system indirectly distinguishes (describes) between pasture and feedlot animals may be more relevant when the tenderness of particularly higher connective tissue cuts and when other quality characteristics are considered, such as fat colour and flavour. Wood et al. (2003) and Campo et al. (2006) reported that the fatty acid composition of pasture and grain fed animals differ and that these differences relate to differences (not preferences) in taste (flavour, juiciness, aroma). Sañudo et al. (1998) described the significance of culinary cultural background on the acceptance of meat coming from pasture or feedlots, thereby indicating preferences for flavour or taste based on experience. These studies emphasise the fact that the description (through classification) of two products that could be experienced differently by different consumers but without one-sided preference, is probably the main objective of classification if variation in consumer preferences is expected.

There are of course methods and systems well documented to overcome most of the variation in final quality. The question remains whether these "control" measures should form part of a grading system and if it is practical to integrate them into a grading system. Bindon \& Jones (2001) described the Australian industry as very similar (though on a larger scale) to that of South Africa with diverse base of climatic extremes, a large breed and breed cross diversity, including a proportion of high Bos indicus content, animal management systems and slaughter and processing facilities. These combinations of different cattle type, age and production system all contribute to extreme variability in carcass quality experienced by the Australian consumer in the 1990s with added effects of variation in cut properties and cooking procedures (Polkinghorne et al., 2008). The development and evolution of the MSA beef grading system followed with the industry identifying two key strategic imperatives for a meat industry strategic plan: to supply a more consistent product and to accurately describe the palatability of this product. Taking this into consideration, several key questions were addressed, viz: 
- Is the consumers' reference framework (terms of reference) for eating quality the same across consumer groups (demographics)?

- How should consumer standards be set?

- How should product quality be measured?

- Did the existing grading systems perform according to the expectations of the different levels of the industry?

The last two questions relate to the main objective of our discussion, while the first two relate to consumer experience and relation to grading or classification. Strictly speaking the implementation of the system was not only for grading purposes but to uplift the whole image of beef to the consumer. Smith et al. (2008) described the system as (a) one with a quality control mentality incorporating production or processing factors that affect beef palatability, and (b) allowing mid-course correction in the product of harvest animals. This is in contrast to systems such as the USDA and other grading and classification systems that rely solely on after-the-fact sorting based only on differences in quality-indicating carcass traits.

The MSA grading system has been developed to predict the eating quality of individual cuts when aged for a defined number of days and cooked by a specified method (Watson et al., 2008a). The prediction is made by a computerised model that calculates the interaction of a range of inputs to produce an MQ4 score (a consumer score incorporating flavour, juiciness, tenderness and overall acceptability; four variables) expressed in points between 0 and 100. Grades are assigned to each cut on the basis of estimated MQ4 points with those $<46$ deemed unsatisfactory, $47-63$ graded three star (good everyday), $64-76$ graded four star (better than everyday) and $>76$ graded five star (premium quality) (Table 2 and 3). There is therefore no carcass grade as such. The inputs mentioned above have been researched and found as major contributors to final quality and satisfaction of the consumer. Pre-slaughter issues are breed, weight for age and growth rate, hormonal growth implants (HGPs), marbling and fatness, gender, stress and management practices. Postslaughter practices are $\mathrm{pH}$ and temperature paths, hanging and aging and cooking method. The inclusion of each factor was discussed and motivated at length by Polinghorne et al. (2008) and Watson et al. (2008a). The following gives a brief description of the effect of each factor as motivated through numerous research trials:

a) A negative relationship exist between eating quality of the loin and levels of Bos indicus content, while no significant differences in eating quality is found among British and continental breeds. Meat Standards Australia measures the amount of indicus by scoring the \% Bos indicus before slaughter and measuring the hump ( $m$. rhomboideus) height after slaughter. A certain cut-off value is used to prevent accidental penalisation of certain Bos taurus breeds.

b) As discussed earlier, research showed that animals growing faster within a group (the same age) produced more tender meat. Dentition was found to be a poor predictor of quality related to age and therefore ossification scores are used combined with the weight of the animal within its age, therefore indicating its growth rate. Most carcasses for the domestic markets in Australia are relatively young and fall into the A maturity group.

c) Consumer data confirm a relationship between marbling and consumer scores which varied widely among cuts. Thompson (2004) and Watson et al. (2008b) reported that marbling alone explain a consistent but relatively low proportion $(15-20 \%)$ of the variation in consumer or trained panel scores of the loin muscle but little of the variation among cuts in the carcass is explained by marbling. In addition to marbling fat, a minimum rib fat thickness of $3 \mathrm{~mm}$ is used as censoring variable.

d) HGPs were found to have negative effect on eating quality, that it varied by muscle and the effect was reduced, but not eliminated by aging (Thompson et al., 2008; Watson, 2008; Watson et al., 2008c). It also showed a breed type x HGP interaction and that HGPs affected marbling and ossification separately.

e) The effect of gender on eating quality was small but was nevertheless included and differentially applied for various muscles and further adjusted according to ossification (Watson et al., 2008b). Bulls would not be included.

f) Various studies (Butchers et al., 1998; Ferguson et al., 2007a; b) describe the effect of stress on, not only tenderness, but also juiciness. Stress is recorded by the origin of the animals, time off feed, and by time restrictions for mixing of groups of animals. Top grades animals are not allowed from sale yards and should be transported to the abattoir directly from the producer. In addition, a final $\mathrm{pH}$ value of 5.7 is used as cut-off criterion and indicator of stress history. 
g) Post slaughter conditions ( $\mathrm{pH}$ change and chilling rate) have been described by Marsh (1954), Marsh et al. (1987), Dransfield (1994) and various others as most important factors controlling tenderisation. The management of the $\mathrm{pH} /$ temperature path to rigor mortis are used to determine if the carcass falls within an "abattoir window" of $12{ }^{\circ} \mathrm{C}$ and $35{ }^{\circ} \mathrm{C}$ at the point when $\mathrm{pH}$ reaches 6.0 (Thompson et al., 2006). Muscle entering rigor $(\mathrm{pH}=6)$ at too high (heat rigor and increased autolyses of proteolytic enzymes) or too low (cold shortening) temperatures is detrimental to tenderness and tenderness development.

h) Carcass hanging method has an effect on eating quality of various muscles and depending on chiller conditions results in an improvement in palatability especially in extreme chilling conditions (too high or low rigor temperatures). When hanging carcasses by the aitch bone (obturator foramen: tender stretch) or other variations thereof instead of Achilles tendon, tenderness of the loin and certain muscles of the buttock is increased through stretching and inhibition of shortening during rigor mortis.

i) Post mortem aging increase tenderness in general but the effect varies by muscle and is a function of connective tissue and fibre type (proteolytic enzymes) properties and post-slaughter conditions (Bouton \& Harris, 1972; Shorthose \& Harris, 1990; Dransfield, 1994; Hwang \& Thompson, 2001b).

j) Cooking method (dry and moist heat) also affects different muscles differently and is the final criterium for the system (Watson et al., 2008b).

The grading model has evolved from a fixed parameter 'Pathway' approach, to a computer model that predicts consumer scores for 135 'cut by cooking method' combinations for each graded carcass (Tables 2 and 3).

Table 2 Example of Meat Standards Australia model input for a sample carcass (Adopted from, Watson et al., 2008b)

\begin{tabular}{lclc}
\hline Description & Format & Name & Input \\
\hline Estimated \% Bos indicus & \% or cross if doubt & EPBI & 25 \\
Animal sex type & $\mathrm{M} / \mathrm{F}$ & $\mathrm{Sex}$ & $\mathrm{M}$ \\
Hormone growth promotant & Yes or ? / No & $\mathrm{HGP}$ & $\mathrm{N}$ \\
Milk fed vealer & Yes / No & $\mathrm{MFV}$ & $\mathrm{N}$ \\
Sale yard & Yes / No & SIYrd & $\mathrm{N}$ \\
Rinse / Flush & Yes / No & $\mathrm{RnFl}$ & $\mathrm{N}$ \\
Hot standard carcass weight & Weight in kg & HSCW & 280 \\
Hang method & AT/TS/TL/TC/TX & Hang & $\mathrm{TS}$ \\
Hump height & mm & Hump & 5 \\
Ossification USDA & USDA measure & uoss & 120 \\
Marbling USDA & USDA measure & umb & 350 \\
Rib fat & mm & $\mathrm{RbFt}$ & 5 \\
Ultimate pH & Metered Temp & UpH & 5.5 \\
Loin temp. at grading & & $\mathrm{Utmp}$ & 3 \\
Days of aging from kill & Days aged & Age & 21 \\
\end{tabular}

Hang method: AT - carcasses suspended by the Achilles tendon; TL - suspended from the sacral ligament; TC - carcasses which were prepared using the tender cut procedure; TX - suspended from the obdurate foramen. 
Table 3 Example of Meat Standards Australia model output for a sample carcass (Adopted from, Watson et al., 2008b)

\begin{tabular}{|c|c|c|c|c|c|c|c|}
\hline \multirow{2}{*}{ Cut } & \multirow{2}{*}{ Muscle } & \multicolumn{6}{|c|}{ Cooking method } \\
\hline & & GRL & RST & SFR & TSL & SCT & CRN \\
\hline Spinalls & SPN081 & 5 & 4 & 5 & 4 & & \\
\hline Tenderloin & TDR034 & 5 & & 4 & & & \\
\hline Tenderloin & TDR062 & 5 & 4 & 5 & 4 & & \\
\hline Tenderloin & TDR063 & 4 & & & & & \\
\hline Cube roll & CUB045 & 4 & 4 & 4 & 4 & & \\
\hline Striploin & STA045 & 4 & 4 & 4 & 4 & & \\
\hline Striploin & STP045 & 4 & 4 & 4 & 4 & & \\
\hline Oyster blade & OYS036 & 3 & 3 & 4 & 4 & & \\
\hline Blade & BLD095 & & & & & & \\
\hline Blade & BLD096 & 3 & 3 & 3 & 3 & 4 & \\
\hline Chucktender & CTR085 & & 3 & 3 & 3 & 4 & \\
\hline Rump & RMP131 & 4 & 4 & 4 & 4 & 4 & \\
\hline Rump & RMP231 & 4 & 4 & 4 & 4 & & \\
\hline Rump & RMP005 & 4 & & 4 & 5 & & \\
\hline Rump & RMP032 & & & 4 & 5 & & \\
\hline Rump & RMP087 & & 3 & 4 & 4 & 4 & \\
\hline Knuckle & KNU066 & 3 & 4 & 4 & 4 & 3 & \\
\hline Knuckle & KNU098 & & & 4 & 4 & 4 & \\
\hline Knuckle & KNU099 & 3 & 3 & 3 & 3 & 3 & \\
\hline Knuckle & KNU100 & & & 4 & 4 & 4 & \\
\hline Outside flat & OUT005 & & 3 & 3 & 4 & 4 & 3 \\
\hline Outside flat & OUT029 & & & 3 & 4 & 3 & \\
\hline Eye round & EYE075 & 3 & 3 & 3 & 3 & 3 & 3 \\
\hline Topside & ТОР001 & 3 & & 3 & 4 & 3 & \\
\hline Topside & ТОР033 & 3 & & 3 & 4 & 4 & \\
\hline Topside & ТОР073 & 3 & 3 & 3 & 4 & 4 & \\
\hline Chuck & СHK068 & & & 3 & 3 & 4 & \\
\hline Chuck & СHK074 & 4 & 3 & 3 & 4 & 4 & \\
\hline Chuck & CHK078 & 3 & 3 & 3 & 3 & 4 & \\
\hline Chuck & CHK081 & & & 3 & 4 & & \\
\hline Chuck & CHK082 & & & 3 & 3 & & \\
\hline Thin-flank & TFL051 & & & 3 & & 3 & \\
\hline Thin-flank & TFL052 & & & 4 & 4 & & \\
\hline Thin flank & TFL064 & & & 4 & 3 & 4 & \\
\hline Rib-blade & RIB041 & & & 3 & & & \\
\hline Brisket & BRI056 & & & & 3 & 3 & \\
\hline Brisket & BBI057 & & & & 3 & 4 & \\
\hline Shin & FQshin & & & & & 4 & \\
\hline Shin & HQshin & & & & & 4 & \\
\hline Intercostal & INT037 & & & 3 & & & \\
\hline
\end{tabular}

Cooking methods: GRL - grill; RST - roast; SFR - stir-fry; TSL - thin slice; SCT - slow cook; CRN - corned. 
The practical implications of the MSA Grading system in terms of recoding were described by Smith et al. (2008) and could be summarised as follows:

- MSA model data inputs from the supplier declaration are percentage Bos indicus, HGP implant status, milk-fed veal 'yes' or 'no', and if from a sale yard.

- Inputs from the slaughter floor are carcass suspension method, whether a vascular infusion treatment has been applied, carcass weight (in $\mathrm{kg}$ ) and sex.

- Inputs entered in the chiller from the quartered carcass are also defined under AUS-MEAT chiller assessment language and are identical to the AUS-MEAT language classification described above for rib fat, meat colour and fat colour. Of these, the model algorithm only uses rib fat for computation, meat and fat colour being censoring variables applied commercially to meet trace appearance standards.

- Additional MSA specific inputs are measured either on the slaughter floor or chiller: MSA marbling standard, maturity (or ossification), hump height, ultimate $\mathrm{pH}$ and the speed at which $\mathrm{pH}$ declines from the live state $(\sim \mathrm{pH}=7.0)$ to the ultimate $\mathrm{pH}$ ( $\mathrm{pH} 5.3$ to 5.7 is optimal) combined with temperature.

Measured against the criteria for a successful grading or classification scheme, viz. Accuracy, Simplicity, Ease of application, Cost, Measures against tampering, it probably only honours the first and last point. It is estimated that approximately $20-30 \%$ of the Australian beef kill is MSA graded. Indeed Australian research has shown that up to $50 \%$ of meat graded is miss-categorised when compared with consumers' assessments (Thompson, 2002). In summary, the MSA scheme is less about carcase description and more about Quality Assurance and conditions imposed in the abattoir.

\section{Should South Africa consider the MSA system?}

There is no doubt that the MSA system would probably have the best outcome in terms of consumer satisfaction. It is in fact a palatability-assured-critical-control-point (PACCP) approach which is integrated into a grading system aimed at maximum consumer satisfaction for a number of cuts prepared according to different cooking methods. In this regard it differs from all other systems. It should be mentioned that certain adjustments will need to be made if the system is applied in other countries, e.g. marbling will have less emphasis in South Africa, while a beta agonist factor in the production system part would have to be included. However, considering our criteria for maximum uptake by all sectors of the industry, the system relies heavily on the integrity of the producer and a very well organised pre-harvest, harvest and post-harvest system with excellent traceability in place (referring to ease of application). For vertically integrated operations (feedlot, slaughterhouse and processing plant) these criteria may be in place but it could be argued that the criteria are already used (partly) by them and that classification (or grading) is not as essential to these operations as to the rest of the industry where every sector operates on its own and the product changes ownership at each point. In addition, the system is probably expensive (cost) and requires much higher technical skills (simplicity) than the current system.

\section{Conclusion}

Considering all the systems discussed in this document, none of them or even selected criteria adopted from them would significantly improve the SA system in our opinion.

If existing documentation is taken into account we can conclude that the current criteria of the South African classification system are inadequate to define quality for different classes if tenderness of particularly low connective tissue cuts is the most important quality aspect. However, the system indirectly distinguishes (describes) between pasture and feedlot animals and should be able to describe or distinguish tenderness of particularly higher connective tissue cuts and other quality characteristics, such as fat colour and flavour. Probably a more ideal system would be to describe quality characteristics for carcasses originating from pasture and feedlot separately. Further development within these categories will then for feedlot animals consist of the utilisation or not (combination and type) of HGP's and beta agonists and will focus on tenderness outcomes. For pasture animals age would play a much more prominent role when tenderness of particularly the higher connective tissue cuts is considered, while additional characteristics such as fat and meat colour could be scored as well. For both systems, however, the variability caused by pre-harvest and harvest conditions still remains a challenge to be taken up in a classification system due to 
reasons mentioned before and tenderness variation especially for low connective tissue cuts can still not be captured easily by single or even easily applied multiple recordings and remains the biggest hurdle.

Finally, although it was speculated, with good support from the literature, that grain fed animals supplemented with a beta agonist will probably produce tougher meat (various cuts) than older pasture fed animals, this was never tested and published in SA and should be addressed in future research.

\section{Acknowledgements}

Elsabe Gagiano for her great effort in the technical preparation of this document.

\section{References}

AHDB Industry Consulting, 2008. Review of the EU Carcass Classification System for Beef and Sheep.

Anon, 1974. Handbook of Australian meat. Aust. Meat Board, Second Edition. ISBN 0642947988.

Anon, 2001. American Meat Science Association. Meat evaluation handbook. Savoy, Illinois, USA: Am. Meat Sci. Ass. ISBN 0-9704378-0-3.

Anon, 2006a. Leaders in delivering services to the meat and livestock industry. Brisbane: AUS-Meat Limited accessed on the 1/2/2010, http://www.ausmeat.com.au/media/2727/corporate-a4.pdf).

Anon, 2006b. Sensory evaluation of loin muscle from carcasses of different age classifications slaughtered at two Meatco operated abattoirs. Technical report for Meatco Pty Ltd, Namibia by PE Strydom, Agricultural Research Council of South Africa.

Anon, 2009. Beef information centre - Canadian beef grading standards. http://www.canadianbeef.info/ca/ en/fs/quality/Standards/default.aspx accessed on the 30/4/2010.

Bindon, B.M. \& Jones, N.M., 2001. Cattle supply, production systems and markets for Australian beef. Aust. J. Exp. Agric. 41, 861-877.

Bouton, P.E. \& Harris, P.V., 1972. The effects of some post-slaughter treatments on the mechanical properties of bovine and ovine muscle. J. Food Sci. 37, 539-543.

Bouton, P.E., Ford, A.L., Harris, P.V., Shorthose, W.R., Ratcliff, D. \& Morgan, J.H.L., 1978. Influence of animal age on the tenderness of beef: Muscle differences. Meat Sci. 2, 301-311.

Butchers, A.D.M., Ferguson, D.F., Devine, C.E. \& Thompson, J.M., 1998. Interaction between preslaughter handling and low voltage electrical stimulation and the effect on beef quality. Proc. $44^{\text {th }}$ Int. Cong. Meat Sci. Technol, Barcelona, Spain. pp. 1050-1052.

Campo, M.M., Nute, G.R., Hughes, S.I., Enser, M., Wood, J.D. \& Richardson, R.I., 2006. Flavour perception of oxidation in beef. Meat Sci. 72, 303-311.

Crosley, R.I., Heinze, P.H. \& Naudé, R.T., 1994. The relationship between beef tenderness and age classification in the South African Beef carcass classification system. Proc. $40^{\text {th }}$ Int. Cong. Meat Sci. Technol, The Hague, Netherlands S-III.15, 34-35.

Dransfield, E., 1994. Optimisation of tenderisation, ageing and tenderness. Meat Sci. 36, 105-121.

Dunshea, F.R., D’Sousa, D.N., Pethick, D.W., Harper, G.S. \& Warner, R.D., 2005. Effect of dietary factors and other metabolic modifiers on quality and nutritional value of meat. Meat Sci. 71, 8-38.

Ferguson, D.M., Shaw, F.D. \& Stark, J.L., 2007a. The effect of reduced lairage duration on beef quality. Aust. J. Exp. Agric. 47, 770-773.

Ferguson, D.M., Warner, R.D., Walker, P.J. \& Knee, B., 2007b. Evaluation of the effect of cattle marketing method on beef quality and palatability. Aust. J. Exp. Agric. 47, 774-781.

Frylinck, L., Strydom, P.E. \& Snyman, J.D., 2009. Subcutaneous fat colour - an indication of beef eating quality? Proc. $55^{\text {th }}$ Int. Cong. Meat Sci.. Technol, 16-21 August 2009, Copenhagen, Denmark, PE 7.43.

Government Notice No. 1548 of 16 October 1936. Grading of agricultural produce on Johannesburg. Government Gazette of the Union of South Africa 106 (2385) 1-12.

Government Notice No. 992 of 20 May 1949. Grading and marking of meat. - Amendment. Extraordinary Government Gazette of the Union of South Africa (24/03/2010) Phillip Strydom - A1-Beef tenderness model popular - Phase 2.doc, Page 6156 (4168) 1-3.

Government Notice No. 846 of 6 April 1951. Grading and marking of meat sold in certain areas. Amendment. Extraordinary Government Gazette of the Union of South Africa 164 (4575) 1-2. 
Government Notice No. R.1730 of 9 October 1970. Regulations regarding the grading and marking of meat which is sold in certain regions of the Republic of South Africa. - Amendment. Government Gazette of the Republic of South Africa 64 (2866) (Regulation Gazette No. 1343) 1-4.

Government Notice No. R.1239 of 16 July 1971. Regulations regarding the grading and marking of meat which is sold in certain regions of the Republic of South Africa. - Amendment. Government Gazette of the Republic of South Africa 73 (3215) (Regulation Gazette No. 1473) 40-41.

Government Notice No. R.1010 of 8 May 1981. Regulations regarding the classification, grading and marking of meat which is intended to be sold in the Republic of South Africa. Government Gazette of the Republic of South Africa 191 (7573) (Regulation Gazette No. 3191) 214.

Government Notice No. R.342 of 19 March 1999. Regulations regarding the classification and marking of meat. Government Gazette of the Republic of South Africa, 19 March 1999.

Hunter, R.A., 2010. Hormonal growth promotant use in the Australian beef industry. Anim. Prod. Sci. 50, 637-659.

Hwang, I.H. \& Thompson, J.M., 2001a. The effect of time and type of electrical stimulation on the calpain system and meat tenderness in beef longissimus dorsi muscle. Meat Sci. 58, 135-144.

Hwang, I.H. \& Thompson, J.M., 2001b. The interaction between $\mathrm{pH}$ and temperature decline early postmortem on the calpain system and objective tenderness in electrically stimulated beef Longissimus dorsi muscle. Meat Sci. 58, 167-174.

Hwang, I.H., Devine, C.E. \& Hopkins, D.L., 2003. The biochemical and physical effects of electrical stimulation on beef and sheep meat tenderness. Meat Sci. 65, 677-691.

Hope-Jones, M., Strydom, P.E., Frylinck, L. \& Webb, E.C., 2010. The efficiency of electrical stimulation to counteract the negative effects of $\beta$-agonists on meat tenderness of feedlot cattle. Meat Sci. 86, 699-705.

Klingbiel, J.F.G., 1984. Development of a grading system for beef carcasses. D.Sc. (Agric) thesis, University of Pretoria, South Africa.

Lawrence, T.E., Whatley, J.D., Montgomery, T.H. \& Perino. L.J., 2001. A comparison of the USDA ossification-based maturity system to a system based on dentition. J. Anim. Sci. 79, 1683-1690.

Lawrence, T.E., Whatley, J.D., Montgomery, T.H., Perino, L.J. \& Dikeman, M.E., 2001. Influence of dental carcass maturity classification on carcass traits and tenderness of longissimus steaks from commercially fed cattle. J. Anim. Sci. 79, 2092-2096.

Lunt, D.K., Smith, G.C., Savell, J.W., Cross, H.R. \& Smith, S.B., 1989. Ether-extractable fat in longissimus muscles from beef carcasses with the same marbling scores but different Yield Grades. J. Food Sci. 54, 1364-1366.

Marsh, B.B., 1954. Rigor mortis in beef. J. Sci. Food Agric. 5, 70-75.

Marsh, B.B., Ringkob, T.P., Russel, R.L., Swartz, D.R. \& Pagel, L.A., 1987. Effects of early post-mortem glycolytic rate on beef tenderness. Meat Sci. 21, 241-248.

Perry, D. \& Thompson, J.M., 2005. The effect of growth rate during back grounding and finishing on meat quality traits in beef cattle. Meat Sci. 69, 691-702.

Polkinghorne, R., Thompson, J.M., Watson, R., Gee, A. \& Porter, M., 2008. Evolution of the Meat Standards Australia (MSA) beef grading system. J. Anim. Sci. 80, 1351-1359.

Polkinghorne, R. \& Thompson, J.M., 2010. Meat standards and grading - A world view. Meat Sci. 86, 227-235.

Purchas, R.W., Burnham, D.L. \& Morris, S.T., 2002. Effects of growth potential and growth path on tenderness of beef longissimus muscle from bulls and steers. J. Anim. Sci. 80, 3211-3221.

Quinn, F., 1999. Tracing the future of meat. Proc. Wrld. Meat Congr. 12 (2), 1-10.

Rodas-Gonsález, Huerta-Leidenz, N., Jerez-Timaure, N. \& Miller, M.F., 2009. Establishing tenderness thresholds of Venezuelan beef steaks using consumer and trained sensory panels. Meat Sci. 83, 218-223.

Sañudo, C., Sanchez, A. \& Alfonso, M., 1998. Small ruminant production systems and factors affecting lamb meat quality. Meat Sci. 49, S29-S64.

Savell, J.W., Cross, H.R. \& Smith, G.C., 1986. Percentage of ether-extractable fat and moisture content of beef longissimus muscle as related to USDA marbling score. J. Food Sci. 51, 838-840.

Schönfeldt, H.C. \& Strydom, P.E., 2011. Effect of age and cut on tenderness of South African beef. Meat Sci. 87, 206-218. 
Shackelford, S.D., Koohmaraie, M., Cundiff, L.V., Gregory, K.E., Rohrer, G.A. \& Savell, J.W., 1994. Heritabilities and phenotypic and genetic correlations for bovine post rigor calpastatin activity, intramuscular fat content, Warner-Bratzler shear force, retail product yield and growth rate. J. Anim. Sci. 72, 857-863.

Shook, J.N., Van Overbeke, D.L., Scanga, J.A., Belk, K.E., Savell, J.W., Lawrence, T.E., Morgan, J.B., Griffin, D.B., Hale, D.S. \& Smith, G.C., 2008. The National Beef Quality Audit 2005. Phase I. Views of producers, packers and merchandisers on current quality characteristics of the beef industry. Professional Animal Scientist 24, 189-197.

Shorthose, W.R. \& Harris, P.V., 1990. Effect of animal age on the tenderness of selected beef muscle. J. Food Sci. 55, 1-8.

Smith, G.C., Carpenter, Z.L., Cross, H.R., Murphey, C.E., Abraham, H.C., Savell, J.W., Davis, G.W., Berry, B.W. \& Parrish, F.C., 1984. Relationship of USDA marbling scores to palatability of cooked beef. J. Food Qual. 7, 289-308.

Smith, G.C., Savell, J.W., Cross, H.R., Carpenter, Z.L., Murphey, C.E., Davis, G.W., Abraham, H.C., Parrish, F.C. \& Berry, B.W., 1987. Relationship of USDA quality grades to palatability of cooked beef. J. Food Qual. 10, 269-286.

Smith, G.C., Tatum, J.D. \& Belk, K.E., 2008. International perspective: characterisation of United States Department of Agriculture and Meat Standards Australia systems for assessing beef quality. Aust. J. Exp. Agric. 48, 1465-1480.

Steenkamp, J.D.G., 1970. The effect of breed and nutritional plane on the chronology of teeth eruption in cattle. Rhod. J. Afric. Res. 8, 3-13.

Strydom, P.E., Frylinck, L. \& Smith, M.F., 2005. Should electrical stimulation be applied when cold shortening is not a risk? Meat Sci. 70, 733-742.

Tatum, J.D., 2006. 'Pre-harvest cattle management practices for enhancing beef tenderness.' (National Cattlemen's Beef Association: Centennial, CO).

Thompson, J., 2002. Managing meat tenderness. Meat Sci. 62, 295-308.

Thompson, J.M., 2004. The effects of marbling on flavour and juiciness scores of cooked beef, after adjusting to a constant tenderness. Aust. J. Exp. Agric. 44, 645-652.

Thompson, J.M., Perry, D., Daly, B., Gardner, G.E., Johnston, D.J. \& Pethick, D.W., 2006. Genetic and environmental effects on the muscle structure response post-mortem. Meat Sci. 74, 59-65.

Thompson, J.M., McIntyre, B.M., Tudor, G.D., Pethick, D.W., Polkinghorne, R. \& Watson, R., 2008. Effects of hormonal growth promotants (HGP) on growth, carcass characteristics, the palatability of different muscles in the beef carcass and their interaction with aging. Aust. J. Exp. Agric. 48, 1405-1414.

Van Wyk, G.L., Frylinck, L., Strydom, P.E. \& Snyman, J.D., 2008. Effects of age, pasture- and feedlot conditions on energy metabolism and meat quality. $54^{\text {th }}$ International Congress of Meat Science and Technology. 10-15 August 2008. Cape Town, South Africa.

Watson, R., 2008. Meta-analysis of the published effects of HGP use on beef palatability in steers as measured by objective and sensory testing. Aust. J. Exp. Agric. 48, 1425-1433.

Watson, R., Polkinghorne, R. \& Thompson, J.M., 2008a. Development of the Meat Standards Australia (MSA) prediction model for beef palatability. Aust. J. Exp. Agric. 48, 1368-1379.

Watson, R., Gee, A., Polkinghorne, R. \& Porter, M., 2008b. Consumer assessment of eating quality development of protocols for Meat Standards Australia (MSA) testing. Aust. J. Exp. Agric. 48, 1360-1367.

Watson, R., Polkinghorne R., Gee, A., Porter, M., Thompson, J.M., Ferguson, D., Pethick, D. \& McIntyre, B., 2008c. Effect of hormonal growth promotants on palatability and carcass traits of various muscles from steer and heifer carcasses from a Bos indicus-Bos taurus composite cross. Aust. J. Exp. Agric. $48,1415-1424$.

Weiner, G. \& Forster, 1982. Variation in the age at emergence of incisor teeth in cattle of different breeds. Anim. Prod. 35, 367-373.

Wood, J.D., Richardson, R.I., Nute, G.R., Fisher, A.V., Camp. M.M., Kasapidou, E., Sheard, P.R. \& Enser, M., 2003. Effects of fatty acids on meat quality: a review. Meat Sci. 66, 21-32.

Wythes, J.R. \& Shorthose, W.R., 1991. Chronological age and dentition effects on carcass and meat quality of cattle in northern Australia. Aust. J. Exp. Agric. 31, 145-152. 